\title{
A importância do bem receber no espaço público: estudo de caso da empresa RIOTUR e seu serviço de informações turísticas
}

The importance of well receiving in the public area: case study of the Riotur company and its tourism information service

La importancia del bien recibir en el espacio público: estudio de caso de la empresa Riotur y su servicio de informaciones turísticas

Patricia Elizabeth de Souza Santiago

Universidade Federal Rural do Rio de Janeiro

DOI: https://doi.org/10.18472/cvt.19n1.2019.1355

(UFRuralRJ), Brasil

Redalyc: http://www.redalyc.org/articulo.oa?

patriicia.tur@hotmail.com

Viviane Soares Lança

Universidade Federal Rural do Rio de Janeiro

(UFRuralRJ), Brasil

lanca.viviane@gmail.com id $=115459473008$

Recepção: 03 Novembro 2016

Aprovação: 13 Julho 2018

\section{Resumo:}

A hospitalidade é primordial para o turismo e, no âmbito da cidade, se traduz na disponibilidade de serviços, estruturas e equipamentos turísticos eficientes. $\mathrm{O}$ visitante, por meio de sua percepção subjetiva, avalia o destino como hospitaleiro ou inospitaleiro, o que pode acarretar no seu retorno ou em uma propaganda negativa do local visitado. Entre os serviços hospitaleiros proporcionados ao turista na cidade do Rio de Janeiro está o de informações turísticas, prestado pela Empresa de Turismo do Município do Rio de Janeiro (Riotur). Nesse contexto, o objetivo deste trabalho foi apresentar a realidade da empresa em relação à qualidade e eficiência de suas informações, baseando-se em opiniões de turistas e dos próprios funcionários da empresa. Trata-se de uma pesquisa descritiva de cunho qualitativo, em que se adotou como método a investigação bibliográfica e documental, além de entrevistas semiestruturadas a turistas usuários do serviço e aos trabalhadores da empresa. Por meio da análise realizada constatouse que, apesar do serviço de informações ser bem avaliado e eficiente na visão do turista, existem lacunas e melhorias que apenas o agente de informações consegue identificar.

PalaVRas-chaVe: Hospitalidade, Riotur, Informações turísticas, Cidade.

\section{Resumen:}

La hospitalidad es primordial para el turismo y, en el ámbito de la ciudad, se traduce en la disponibilidad de servicios, estructuras y equipos turísticos eficientes. El visitante, a través de su percepción subjetiva, evalúa el destino como hospitalario o inhospitalario, lo que puede acarrear a su regreso o en una propaganda negativa del lugar visitado. Entre los servicios hospitalarios proporcionados al turista en la ciudad de Río de Janeiro está el de informaciones turísticas, prestado por la Empresa de Turismo del Municipio de Río de Janeiro (Riotur). En este contexto, el objetivo de este trabajo fue presentar la realidad de la empresa en relación a la calidad y eficiencia de sus informaciones, basándose en opiniones de turistas y de los propios empleados de la empresa. Se trata de una investigación descriptiva de cuño cualitativo, en que se adoptó como método la investigación bibliográfica y documental, además de entrevistas semiestructuradas a turistas usuarios del servicio ya los trabajadores de la empresa. Por medio del análisis realizado se constató que a pesar de que el servicio de informaciones es bien evaluado y eficiente en la visión del turista, existen lagunas y mejoras que sólo el agente de información puede identificar.

Palabras Clave: Hospitalidad, Riotur, Informaciones turísticas, Ciudad.

\section{Abstract:}

Hospitality is the main focus of tourism, and with regards to a city, this translates into the availability of services, structure and provisions for the tourist. Tourists, through their subjective perception, evaluate the hospitality of the destination using these factors, and their experiences will lead them to form either positive or negative impressions. Among the hospitality services offered 
to tourists in the city of Rio de Janeiro, is the tourist information provided by Empresa de Turismo do Município do Rio de Janeiro (Riotur). The purpose of this work was to analyze the company's reality regarding the quality and efficiency of its information, based on the opinions of tourists and the company's employees. This is a qualitative descriptive research, in which bibliographical and documentary research was adopted as method, as well as interviews with tourists who are users of the service and workers of the company. Through the survey, it was found that despite the information service be rated good and efficient from the tourists, there are gaps and improvements that only the information agent can identify.

KEYWORDS: Hospitality, Riotur, Tourist information, City.

\section{INTRODUÇÃO}

Hospitalidade é a qualidade social que visa a inserção de um visitante de maneira natural e agradável em meio desconhecido (GRINOVER, 2007). O bem receber demanda qualidades inerentes ou adquiridas do anfitrião, que precisa permitir e prover o acolhimento de tal forma que o visitante se sinta bem quisto e confortável. Falhas nesse processo ou seu não cumprimento resulta em encontros inospitaleiros ou em hostilidade.

As hospitalidades social e pública, que dão base a este trabalho, estão relacionadas à dádiva do espaço urbano de proporcionar o bem receber. A hospitalidade social trata dos espaços públicos de convivência, das relações de troca humana e das políticas públicas. Neste contexto, a hospitalidade urbana, vertente da hospitalidade social, é de fundamental importância para o planejamento urbano e gestão turística, já que auxilia na estruturação de uma cidade para que esta esteja adequadamente preparada para a recepção dos visitantes. São pelas cidades que os turistas são atraídos, por concentrarem a essência das tradições e convivência da população autóctone, além de reunir a maioria dos pontos de interesse de visitação. Ao entenderem essa capacidade natural de atratividade, alguns gestores públicos percebem que uma cidade boa para se viver também é uma cidade boa para se visitar (SEVERINI, 2013).

Assim, a informação é elemento fundamental da hospitalidade na atividade turística e um fator-chave para a sensação de bem-estar na experiência do visitante, uma vez que a facilidade de acesso e a eficácia da informação recebida, entre outros fatores, contribuem para a percepção de acolhimento e definição de uma cidade hospitaleira. Dentro desse contexto, a Empresa de Turismo do Município do Rio de Janeiro (Riotur) possui um papel fundamental, atuando na disseminação de informações turísticas por intermédio da distribuição de postos de informação em locais estratégicos da cidade. Os postos de atendimento oferecidos pela Riotur são uma iniciativa da Prefeitura do Rio de Janeiro, atualmente totalizando 14 (quatorze) postos localizados nas zonas Sul, Oeste e centro da cidade, oferecendo recepcionistas bilíngues e material informativo, como mapas e guias programáticos.

Um maior enfoque no estudo da prestação do serviço de informações turísticas, identificando seus acertos e deficiências, poderá ser um diferencial para o fortalecimento da cidade do Rio de Janeiro como destino hospitaleiro. Assim, este trabalho tem como principal finalidade apresentar a realidade da empresa Riotur em relação à qualidade e eficiência de suas informações turísticas a partir de uma análise baseada nas opiniões de turistas e funcionários. Além disso, buscou-se observar a distribuição espacial dos postos da Riotur; verificar o treinamento dos funcionários; visitar os postos da Urca, Aeroporto Santos Dumont, Candelária e Copacabana por se localizarem em pontos de grande fluxo de passagem (entrada e saída de turistas na cidade) e apontar as necessidades de melhorias com embasamento nas opiniões dos turistas e funcionários.

O presente trabalho está estruturado de forma a contextualizar, por meio de revisão bibliográfica, os assuntos acerca da abrangência da hospitalidade pública e da cidade como seu cenário, além da conexão com a atividade turística. Posteriormente, apresenta-se a Riotur e sua relevância no papel do bem-receber do visitante. Por fim, os resultados trazem as impressões hospitaleiras sobre o serviço de informações turísticas da cidade do Rio de Janeiro pelo viés dos turistas e dos próprios funcionários da empresa. 


\section{A ARTE DO BEM RECEBER NO ESPAÇO PÚBLICO}

Para Camargo (2004), a hospitalidade está além da oferta de acomodação, uma vez que se trata de um processo de comunicação interpessoal carregada de conteúdos não verbais e rituais que variam de sociedade para sociedade, mas que tem como único objetivo o vínculo pessoal por meio da percepção de acolhimento. Segundo Mauss (1974), a explicação encontra-se na herança das sociedades arcaicas e na essência da dádiva, uma dinâmica cíclica, em que as pessoas se inserem, de dar, receber e retribuir um presente/caridade recebida. Para Mauss (1974), estes são os três deveres que explicam as relações das sociedades antigas, nas quais o contato humano se estabelecia através de uma dádiva inicial que gerava retribuição, isso implicava em um novo receber e retribuir, e em um processo sem fim de dons e contradons, sendo a hospitalidade responsável por costurar, sedimentar e vivificar o tecido social.

A hospitalidade pública acontece em rituais que se dividem em: recepção, que consiste no acolhimento do visitante nos espaços públicos da cidade; "hospedagem”, que se refere à oferta de aparelhos públicos de recepção, como terminais de transportes e centros de informações; alimentação em ambiente público, que se baseia na oferta de gastronomia em geral, da culinária mais simples às típicas e regionais (sendo por vezes a gastronomia da região o elemento motivacional principal da viagem); e, por fim, entreter em ambiente público, que se constitui na oferta de equipamentos urbanos de lazer e eventos, além da oferta de áreas livres, parques e centros culturais que devem ser planejados essencialmente para a população residente e, consequentemente, para desfrute turístico (CAMARGO, 2004).

\subsection{O contexto atual da hospitalidade e sua ligação com o turismo}

Uma das temáticas que explica o interesse moderno pelo estudo da hospitalidade é a das viagens turísticas, responsável pelo crescente grupo de pessoas que viajam por prazer. Tendo em vista que estas necessitam de acolhimento, encontra-se o cenário perfeito para que a hospitalidade se faça presente. Assim, nos cursos de turismo, a hospitalidade e suas leis precisam ser ensinadas como ética que rege todo e qualquer contato com o turista, a fim de que se entenda que o bem receber é papel fundamental de quem acolhe o outro em sua cidade. É inegável a necessidade de enriquecer a área de estudo da hospitalidade não só com enfoque na hotelaria, mas englobando todos os elementos intangíveis, como a sensação de acolhimento, o reconhecimento da capacitação profissional e informações turísticas que façam os visitantes se sentirem confortáveis.

O estudo e prática da hospitalidade, dentro do contexto turístico, precisam se encarregar da recepção humana de qualidade. A atividade turística é tratada como um setor de serviços dentro da economia e, como consequência, seu sucesso é contabilizado pela receita que gera e número de turistas que atraem e é nessa barreira que a hospitalidade-dádiva, aquela sem trocas financeiras e materiais, encontra dificuldade em se sobressair no mercado competitivo e capitalista atual. A dificuldade consiste em fazer florescer dentro do profissional de turismo a dádiva de desejar tornar a experiência de cada visitante única dentro de um modelo econômico selvagem, exigente e de pouco retorno financeiro.

De acordo com Camargo (2004), a fim de promover a valorização das relações humanas, é necessário repensar o planejamento dos serviços de recepção em geral, não só para o turista, mas também para os residentes quanto ao uso das organizações públicas e privadas. Tendo em vista que, segundo De la Haba e Santamaría (2008 apud GRINOVER, 2009, p. 8), "não existem espaços hospitaleiros, mas, sim, usos hospitaleiros do espaço", seria necessária, então, a instauração de um planejamento turístico e urbano que incluísse, em seu processo, atenção às ações hospitaleiras nos espaços de uso comum, privilegiando, assim, $o$ cotidiano e o lazer do residente e, consequentemente, o do visitante.

Um planejamento turístico ineficiente contribui para experiências turísticas não hospitaleiras, uma vez que os modelos de planejamento existentes, em sua maioria, consistem na programação de atividades e oferta 
de estruturas padronizadas para o turismo de massa, o que torna a experiência impessoal. O que se nota é que o planejamento urbano das cidades pouco se preocupa com sua clareza espacial e visual, não tendo como foco que são nelas que se criam e processam vínculos humanos, pois uma cidade confusa não desperta no visitante o desejo de permanecer e se relacionar. Portanto, é indispensável a compreensão de um sistema de ofertas dentro do turismo que inclua um serviço de prestação de informações turísticas eficaz como exigência predominante para o sucesso da experiência total do visitante.

\subsection{A cidade e a hospitalidade}

A visitação em meio urbano acontece em decorrência de motivações, como o turismo de negócios e eventos, ou pela atratividade natural da cidade como centro de sociabilidade e encontros heterogêneos, pois a atração primária do turista é pela variedade cultural, de lazer e entretenimento dos grandes centros urbanos. Porém, destaca-se a importância da hospitalidade como fator de ampliação do tempo de estada dos visitantes para que se sintam bem acolhidos, desejem retornar à cidade e gerem receita. A importância da hospitalidade pública, portanto, é pautada na proximidade ética que promove, estabelecendo práticas sociais que viabilizem o uso de lugares de interação (SEVERINI, 2013).

A hospitalidade é um conceito subjetivo, ou seja, cada indivíduo pode percebê-la e avaliá-la à sua maneira. Assim, é importante que existam esforços para que os elementos ofertados nos destinos possam criar uma atmosfera o mais confortável possível para que a avaliação psicológica de cada visitante seja próxima do que ele considere hospitaleiro. Portanto, o destino não deve desprezar os riscos de viagem aos quais todos estarão expostos e que podem gerar hostilidade, mas deve investir no estudo e prevenção desses riscos.

Uma cidade é tida como hospitaleira a partir de três dimensões: sua acessibilidade, legibilidade e identidade (GRINOVER, 2006). A acessibilidade urbana está ligada à disponibilidade de acesso a equipamentos públicos presentes na cidade (vias de tráfego, estações de trem e metrô, transporte urbano, etc.) e a aspectos socioeconômicos, como a igualdade de acesso aos equipamentos culturais urbanos indiferentes da classe social ou origem; a legibilidade está associada à leitura da cidade feita pelo visitante, sendo uma categoria espacial da capacidade de cada indivíduo entender a organização dos elementos à volta dele; e, por fim, a identidade se relaciona à autenticidade da história e tradição das edificações, do comércio e das pessoas pertencentes às cidades. Quanto melhor o ambiente oferecido aos cidadãos e turistas para o desenvolvimento de suas atividades, melhor eles se sentirão e mais tempo permanecerão estabelecendo relações sociais mais prazerosas (GRINOVER, 2006).

\section{METODOLOGIA}

Silva e Menezes (2005) relatam que a pesquisa descritiva, como o próprio nome indica, descreve as características do objeto de estudo, como uma população, um fenômeno ou até mesmo "o estabelecimento de relações entre variáveis" (p. 20). Para tanto, depende de instrumentos de coleta de dados, bem como uma observação sistemática, que, em geral, assemelha-se ao levantamento de informações.

Ainda segundo as autoras, um trabalho com caráter qualitativo considera que há um vínculo inseparável entre a objetividade e a subjetividade do sujeito incapaz de ser completamente expresso em números. Em razão disso, "o ambiente natural é a fonte direta para coleta de dados e o pesquisador é o instrumentochave" (p. 20), sendo o processo e toda a sua significação os principais focos da abordagem.

Tendo como base tais colocações, a metodologia utilizada para o desenvolvimento do presente trabalho pautou-se na pesquisa descritiva, com utilização de estudo de caso, a partir de uma abordagem qualitativa com embasamento em material bibliográfico e documental, além de fontes secundárias, como artigos, dissertações, teses e revistas. 
Utilizou-se como instrumento de coleta de dados um questionário semiestruturado composto de 5 (cinco) questões abertas, aplicado a uma amostra aleatória de 35 turistas que visitaram os postos de informação e aceitaram participar da pesquisa, no período de 20 de maio a 13 de junho de 2015. Da mesma forma, outro questionário composto por 10 questões foi aplicado, também utilizando amostragem aleatória, a um total de 30 funcionários que ficam distribuídos nos postos da Urca, Candelária, Copacabana, Aeroporto Santos Dumont e Aeroporto Internacional Tom Jobim (Terminal 1) entre os dias 20 e 30 maio de 2015.

Tais entrevistas foram essenciais para se verificar como é compreendida a hospitalidade praticada pela empresa, se é eficaz no que se propóe e sua importância para a atividade turística. Assim, a partir das respostas obtidas, foi feita tabulação e análise dos dados, o que permitiu a obtenção do cenário de hospitalidade oferecido pela empresa e na cidade, a partir da visão dos turistas e funcionários.

\section{A RIOTUR E SEU PAPEL NA HOSPITALIDADE CARIOCA}

A Riotur foi criada em 14 de julho de 1972, inicialmente nomeada como Empresa de Turismo do Estado da Guanabara com sede instalada no centro do Rio de Janeiro. Em agosto de 1973, com o fim do Estado da Guanabara, realizou-se Assembleia Geral de Constituição da Riotur, quando foi renomeada como Empresa de Turismo do Estado do Rio de Janeiro. Apenas em 6 de maio de 1975, foi vinculada à Secretaria Municipal de Turismo e assumiu a atual denominação, Empresa de Turismo do Município do Rio de Janeiro S.A.

A empresa tem como objetivos principais a captação de fluxos turísticos nacionais e estrangeiros para a cidade do Rio de Janeiro, gerando o ingresso de divisas e o aumento da oferta de empregos para o fortalecimento da economia da cidade mediante ações de marketing. Entre suas competências está a missão de "desenvolver, implementar e manter um plano estratégico de turismo, coordenando a realização e a execução de estudos, pesquisas e programas de interesse para o desenvolvimento da atividade turística do município bem como produzir e ou apoiar grandes eventos na cidade" (PREFEITURA DO RIO DE JANEIRO, 2014, p. 1).

Os Postos de Informações Turísticas são uma iniciativa da Prefeitura do Rio de Janeiro, por intermédio da Secretaria Municipal de Turismo e Riotur (ORLA RIO, 2014). Consiste em um serviço gratuito, em que o turista tem acesso ao material informativo e aos atendentes para auxiliá-los sanando dúvidas e dando informação turística. Até a realização da presente pesquisa ${ }^{[1]}$, os postos de informações turísticas disponibilizados pela empresa estão distribuídos nos seguintes pontos com seus respectivos funcionamentos: Aeroporto Internacional Antônio Carlos Jobim - Terminais I e II (diariamente - 24h), Aeroporto Santos Dumont (diariamente $-6 \mathrm{~h}$ às $22 \mathrm{~h}$ ), Barra (diariamente $-9 \mathrm{~h}$ às $18 \mathrm{~h}$ ), Candelária (segunda a sexta das $9 \mathrm{~h}$ às $18 \mathrm{~h}$ e sábado das $9 \mathrm{~h}$ às $15 \mathrm{~h}$ ), Lapa (diariamente $-9 \mathrm{~h}$ às $19 \mathrm{~h}$ ), Leblon (diariamente $-8 \mathrm{~h}$ às $20 \mathrm{~h}$ ), Urca (diariamente - $8 \mathrm{~h}$ às 20h), Copacabana CIAT (segunda a sexta das $9 \mathrm{~h}$ às $18 \mathrm{~h}$ e sábado das $9 \mathrm{~h}$ às $15 \mathrm{~h}$ ), Copacabana Praia (diariamente - 8h às 21h), Ipanema (diariamente - 8h às 20h), Quinta da Boa Vista (diariamente - $9 \mathrm{~h}$ às $17 \mathrm{~h}$ ), Rodoviária Novo Rio (diariamente - 24h) e Shopping da Gávea (diariamente $-10 \mathrm{~h}$ às $22 \mathrm{~h}$ ).

Segundo dados das estatísticas mensais realizadas pelos próprios funcionários, os postos que recebem maior demanda são aqueles localizados em Copacabana e Ipanema, devido à fama internacional dos bairros e grande número de turistas pela região; na Urca, devido à proximidade ao atrativo turístico do Pão de Açúcar e ao Aeroporto Santos Dumont e na Rodoviária por serem locais de entrada e saída de turistas.

\subsection{A hospitalidade a partir dos materiais disponibilizados pela Riotur}

A Riotur disponibiliza aos turistas em visita ao Rio de Janeiro acesso a mapas, guias turísticos e informações acerca de passeios, programas culturais, históricos, esportes e lazer. O material é produzido pela própria 
empresa. Além do material impresso, o turista pode contar com uma plataforma digital através do website "Visit Rio", onde é possível acessar virtualmente todo o material disponível nos quiosques em português, espanhol ou inglês (VISIT RIO, 2016).

Entre os principais materiais disponibilizados e distribuídos gratuitamente aos turistas estão: o livro Guia do Rio, que consiste em um catálogo de referência para todos os assuntos que o turista desejar obter informações; a revista mensal Guia do Rio, que contém os principais eventos da cidade referentes ao mês corrente, além das principais informações contidas no Guia; o Mapa Turístico Oficial que abrange um recorte do centro, parte da Zona Sul e da Zona Norte com layout mais simples para consultas práticas, bem como mapa das linhas do metrô; e o Mapa Turístico Oficial em formato dobrável, com maior detalhamento de ruas e abrangendo todo o centro, Zona Sul, Barra e parte da Zona Norte. Os dados geográficos dispostos nos mapas são fornecidos à Riotur pelo Instituto Municipal Pereira Passos (IPP) (RIOTUR, 2015).

\subsection{Profissionais: entre a hostilidade e a hospitalidade}

O quadro de profissionais ligados diretamente aos postos de informação da Riotur é composto por funcionários contratados em regime da Consolidação das Leis do Trabalho (CLT) pela empresa terceirizada (Grupo Maza) e por estagiários contratados pela Riotur.

Em geral, os quiosques, locais de trabalho dos funcionários, possuem grande disparidade entre si no que tange à sua estrutura física e equipamentos básicos (tamanho, disponibilidade ou ausência de filtros, bebedouros ou freezer, banheiro, computadores, telefones, ventiladores, entre outros). Como exemplos, citam-se dois postos que possuem layout, tamanho e equipamentos completamente diferentes entre si: o posto do Aeroporto Internacional, localizado dentro do aeroporto, com acesso a facilidades e maior conforto; o posto de Copacabana, localizado em via pública, sem garantias de segurança e exposto a mudanças climáticas; e ainda o posto da Candelária, que além da insegurança e da localização em ruas, oferece espaço mínimo para o número de funcionários.

Baseando-se em pesquisa de campo realizada de março a julho de 2015 e conversas informais com os funcionários, foi possível detectar diversos problemas enfrentados por eles diariamente. Entre eles, citamse a ausência de banheiro em todos os quiosques, fato que os obriga a sair de seu posto em procura de sanitários nas instituições próximas; a incidência de insetos dentro ou na proximidade dos postos que se localizam em vias públicas; falta de segurança, abordagem de moradores de ruas e assaltantes; ausência de um supervisor para problemas imediatos; ausência de facilidades como telefones e ventiladores e até de primeira necessidade como bebedouros e filtros; exposição a fatores climáticos, entre outras dificuldades que a falta de uma estrutura adequada ao trabalho acarreta. Diante de condições insatisfatórias de trabalho, o funcionário, por muitas vezes, não se sente confortável ao trabalhar, esbarrando na sensibilidade de cada um em transmitir isso ou não ao seu trabalho, comprometendo por muitas vezes o atendimento.

Nos quiosques, o ritual da hospitalidade acontece através do funcionário que assume seu papel de anfitrião, pela sua posição de protagonista, detentor de vantagens e conhecimentos e que deve ao turista o acolhimento que desejaria se estivesse em sua situação, ou seja, em país desconhecido com inúmeras novas percepções ao seu redor. Por sua vez, o hóspede é encarnado pelo turista, aquele que penetra na casa (cidade) do outro, sem pedir permissão, sem ser conhecida sua identidade, e, assim, conta apenas com a dádiva e boa vontade do outro para ter boas ou más experiências, logo, considerar hospitaleiro ou não aquele local. Mas saberiam esses funcionários do tão importante papel que possuem? E mais ainda, estariam eles recebendo hospitalidade também por parte da empresa em que trabalham?

Os turistas atuais viajam motivados, também, pela interação humana, pelo desejo de enriquecimento pessoal, por meio do intercâmbio de culturas, logo, o atendente que se propõe a prestar informações em um dos postos, precisa internalizar sentimentos de benevolência ao turista que recebe, doando-lhe compreensão a fim de que haja relacionamento. 
Assim, o visitante é beneficiado a partir do momento que encontra acolhimento e não sente a cidade como um lugar estranho, recebendo informação, bom atendimento, guias turísticos, mapas e linguagem idiomática em forma de serviço. Por sua vez, o benefício do funcionário, sob o contexto da dádiva, é recebido em forma de reconhecimento por parte do turista que tem sua dúvida sanada e demonstra gratidão, contradom gerado em reciprocidade ao dom do bom atendimento oferecido.

Apresentou-se, nesta seção, todo o contexto que tornou necessária a criação dos atuais postos de informações e quais são as características do cenário do serviço prestado pela empresa em questão. Fica claro que a hospitalidade é um item de extrema sensibilidade dentro da atividade turística, pois depende de esforços de diversos agentes públicos e privados, de políticas públicas, de estruturas urbanas, do bem receber da população e de mão de obra qualificada. Assim, constata-se que, apesar de toda ação de marketing da Riotur, o cuidado com o seu funcionário está relegado a segundo plano. Até aqui, foi realizada uma explanação sobre a hospitalidade na Riotur, sendo o tópico seguinte dedicado à discussão resultante da análise das entrevistas realizadas com os turistas e os demais funcionários.

\section{A RIOTUR E SUA PROMOÇÃO DE HOSPITALIDADE}

Como já exposto, o vínculo do turista com a cidade se estabelece por meio das experiências, dos bons serviços que adquire e das pessoas com as quais interage. Assim, o funcionário da empresa Riotur, direta ou indiretamente, é capaz de contribuir com esse vínculo, uma vez que promove melhores experiências através das informações sobre a cidade, contribuindo para a percepção de hospitalidade e viabilizando a interação com a comunidade por meio de dicas de locais de encontro social.

Nesta seção, de forma geral, apresentam-se as opiniões dos dois principais interessados pelo serviço: funcionários e turistas. Essas opiniões foram obtidas por meio de conversas com uma amostra dos turistas que visitaram os postos durante o período de entrevistas e com funcionários que trabalham nos postos visitados. A presente pesquisa foi realizada nos postos de trabalho sob conhecimento e parecer dos gestores e da empresa.

\subsection{A hospitalidade proporcionada pela Riotur na visão dos funcionários}

Os dados apresentados a seguir foram levantados a partir de entrevistas com os funcionários da Riotur, a fim de compreender suas reais motivações e condições de trabalho nos quiosques de informações turísticas. Foram realizadas entrevistas com 18 funcionários e 12 estagiários no período de 20 a 30 de maio de 2015 nos postos da Urca, Candelária, Copacabana, Aeroportos Santos Dumont e Internacional Tom Jobim.

Com base nas explanações feitas durante esta pesquisa, foi possível notar que o trabalho do funcionário de informações turísticas é fundamental, pois aquele que presta atendimento é responsável pela impressão de hospitalidade do visitante no que tange ao preparo informacional da cidade. Ao se dirigir a um posto de informação, o turista se sente dentro de sua zona de conforto, pois subentende que sairá dele com suas dúvidas sanadas, encontrará mapas e materiais informativos sobre o que deseja visitar, além de atendentes que falarão uma língua de seu entendimento.

A problemática em si está na impossibilidade de garantir que todos os atendentes estejam suficientemente treinados para prestar um serviço eficiente de informaçóes turísticas dentro de uma cidade da complexidade e importância do Rio de Janeiro. Isso porque essa cidade disponibiliza inúmeras possibilidades de serviços, informações, detalhes e dicas que necessitam de conhecimento, muitas vezes de vivência pessoal, para serem passadas com fidelidade, e que nem sempre são conhecimentos que o atendente domina, aumentando o risco de informar o turista de forma superficial ou equivocada. Como consequência, o turista se encontra exposto a inúmeros imprevistos, podendo ser colocado em perigo, pagar mais caro em um serviço desnecessariamente, 
perder o horário de um voo, ser enganado por serviços não oficiais, entre vários problemas que uma informação equivocada pode acarretar.

No plano prático, com embasamento na pesquisa realizada e depoimentos dos funcionários, comprova-se que o período de treinamento dado pela empresa, de 1 a 4 dias, em geral, é muito curto para a responsabilidade que será adquirida, levando-se em consideração, por exemplo, que pessoas naturais de outro estado ou cidade são contratadas e não estarão preparadas, em tão pouco tempo, para assumirem um cargo que exija conhecimentos sobre o turismo, transporte e serviços do Rio de Janeiro. Numericamente, 56,6\% dos entrevistados consideraram seus treinamentos regulares ou insuficientes, incluindo três funcionários que assumiram seus cargos sem nenhum tipo de treinamento. Além disso, foi relatado que, na realidade, o conhecimento técnico é adquirido na prática, em convivência com funcionários mais antigos, e que, por vezes, acabam propagando informações erradas e/ou desatualizadas por falta de conhecimento pessoal do que está sendo informado.

Ainda sobre o treinamento, funcionários deram diversas sugestões importantes que poderiam ser utilizadas pela empresa a fim de enriquecer o treinamento e, consequentemente, o serviço de informações turísticas. Entre elas, destacam-se as seguintes opiniões:

"Realização de palestras dinâmicas, mostrando como seria um atendimento ideal, exposição da história da cidade e de seus principais pontos turísticos, suas curiosidades, etc." (Estagiária atuante no posto de informação da Urca).

"Apresentação em slides demonstrando o material de divulgação da empresa e nosso material de trabalho, além de condutas profissionais e normas." (Funcionário atuante no posto de informação do Aeroporto Internacional do Rio de Janeiro).

"Acrescentaria um rodizio pelos postos de trabalho e propostas de visitação guiada pelos principais pontos turisticos da cidade e pontos de interesse ao redor do bairro onde seu quiosque se localiza." (Funcionário atuante no posto de informação da Urca).

Porém, essa é uma deficiência detectada em diversos setores do turismo, pois, de acordo com Neves e Alexandre (2006), o nível de qualificação profissional dos prestadores de serviços de hospitalidade é considerado insuficiente. Segundo eles, o nível educacional, a falta de domínio de outros idiomas, o desconhecimento do cliente, e a despreocupação com as necessidades dos visitantes são alguns dos fatores que atrapalham a evolução da qualidade dos serviços de hospitalidade, mesmo que, no caso da Riotur, não tenham sido percebidos pelos visitantes. "[...] O conhecimento é o grande diferencial das organizações desta sociedade voltada para a prestação de serviços. Por isso, o trabalho em serviços, mesmo que rotineiro, também requer autoaperfeiçoamento e aprendizado contínuos" (DRUKER, 1993 apud NEVES; ALEXANDRE, 2006, p. 3).

E mesmo que essa primeira barreira seja vencida, ou seja, por melhor treinado ou experiente que um atendente possa ser, a boa vontade e disposição em atender precisam estar presentes, e esse é um obstáculo mais difícil a se transpor. Isso porque inúmeros fatores podem afetar negativamente a sensibilidade de um funcionário, como problemas pessoais, ambiente de trabalho ruim, cansaço, má remuneração, turistas insistentes e repetitivos, e o foco principal, a ausência de uma personalidade hospitaleira, que priorize a dádiva do bem receber, colocando os fatores adversos em segundo plano. Numericamente, $66,6 \%$ dos entrevistados afirmaram que as más condições de trabalho influenciam negativamente seus atendimentos em longo prazo, fazendo com que a empatia e a hospitalidade com o turista sejam deixadas de lado.

Em relação ao ingresso na empresa, constata-se que a maioria dos entrevistados é motivada pela credibilidade do nome da Riotur no mercado de trabalho, pois acreditam que a experiência enriquecerá seu currículo futuramente. Numericamente, 15 entrevistados relataram esse motivo, enquanto outros nove escolheram a empresa pelo interesse em trabalhar na prestação de informação ao turista. Entre as outras opções, foram citados: aprimoramento do idioma, condições de trabalho e remuneração, complemento de horas de estágio e indicação de amigos. 
Em relação à eficiência e qualidade do material informativo disponibilizado pela empresa, dos funcionários entrevistados, 20 avaliam o material (guia trimestral, revista mensal e mapas) como completos e eficientes, enquanto 10 dizem que o material apresenta falhas. Este último grupo relatou a existência de informações desencontradas, desatualizadas ou incompletas.

Em relação à localização dos postos, a parcela de entrevistados insatisfeitos afirmou que mudanças seriam bem-vindas. Entre as propostas de mudanças estão a criação de postos em locais como: Zona Norte da cidade; no bairro Cosme Velho na estação do Cristo Redentor ou na estação de metrô do Largo do Machado; na orla do Leme; na Estação Central do Brasil; na Avenida Rio Branco; no bairro de Botafogo; no Rio Centro; no Centro de Tradições Nordestinas - Feira de São Cristóvão; no Aterro do Flamengo; no Jardim Botânico e na Lagoa. Além disso, foi recomendada a alteração da localização de alguns postos já existentes, como o de Ipanema e Leblon, que poderiam ser transferidos para a orla dos respectivos bairros, e o da Lapa, transferido de sua localização lateral aos arcos para uma central a eles, local de mais fácil acesso visual ao turista. Alguns funcionários citaram o posto da Gávea e o da Quinta da Boa Vista como desnecessários, pois recebem um pequeno número de turistas ao dia.

Os funcionários, de maneira geral, estão dispostos a realizar suas funções com qualidade e mostram-se sensíveis à percepção das falhas da empresa. Constatou-se que 16 funcionários afirmam realizar seu trabalho de forma com que os turistas sintam-se satisfeitos com a explicação dada e saiam do posto com suas dúvidas sanadas, enquanto 11 garantem sentir que os turistas ficam satisfeitos com as explicações turísticas, mas sentem dificuldades em entender procedimentos de locomoção ou funcionamento da cidade devido suas barreiras estruturais, além de três funcionários que admitem que os visitantes saem ainda confusos dos postos devido problemas estruturais na cidade.

Questionados sobre os principais problemas da cidade que detectaram desempenhando suas funções, foi possível perceber os seguintes aspectos como sendo determinantes negativos para o fluxo de visitantes: transportes insuficientes, ineficientes ou não articulados (citado 16 vezes); atrativos turísticos caros, falhas na prestação de serviço ou dificuldade de acesso (17 vezes); empresas de turismo com falhas na realização do serviço ou não confiáveis (13 vezes); falta de sinalização viária, como placas indicativas de ruas ou atrativos turísticos (8 vezes); ausência de atividades culturais, festas e programação típica durante todo o ano (2 vezes), além da segurança, citada de forma avulsa (1 vez).

Foi intenção desta pesquisa observar até que ponto os funcionários são ou não influenciados pelas más condições de trabalho no seu trato com o turista. Assim, apenas 10 funcionários do total de entrevistados relataram que conseguem discernir seu atendimento de fatores negativos relacionados ao ambiente de trabalho (relação com colegas e chefes no trabalho, problemas pessoais, má remuneração, entre outros), colocando a hospitalidade em primeiro lugar; enquanto os 20 restantes admitem que esses fatores podem alterar sua forma de atendimento e abalar sua hospitalidade. Entre os relatos, os funcionários afirmam gostar do que fazem, mas não sentem reconhecimento por parte da empresa, que oferece locais de trabalho sem conforto e providências básicas, como água e banheiro, além da remuneração baixa à capacitação deles e, assim, em longo prazo, sentem a impossibilidade de não repassarem suas insatisfaçóes ao atendimento.

Por fim, questionaram-se suas opiniões sobre a relevância de seus próprios atendimentos na hospitalidade da atividade turística e na experiência total do visitante. De forma abrangente, cada agente de informação tem plena noção da importância de seu trabalho, pois todos relataram a relevância do atendimento no posto como primeiro contato do visitante com a cidade, impactando diretamente na imagem percebida do local. Eles discorrem acerca da importância no atendimento para informar, entre outros assuntos, sobre a programação cultural da cidade, a fim de que se propague a cultura carioca. Asseguram que funcionários bem preparados e seguros de suas informações passam confiança ao turista, fazendo com que eles passeiem com mais tranquilidade e retornem, ou sempre procurem um posto em cada local da cidade que visitarem, destacando a empresa como referência. O contrário também pode acontecer, ou seja, um mau atendimento pode fazer com que os turistas não retornem mais aos postos da empresa e conheçam a cidade superficialmente. Relatam 
que, por meio das dicas dadas nos postos, o turista pode planejar sua viagem de forma segura e mais barata, além do primordial, divulgar os atrativos naturais, culturais e de lazer da cidade.

Claro que não se pode estender a todos os funcionários essa característica da empatia e hospitalidade, pois existem relatos de atendimentos realizados de forma ríspida, mas atitudes como essas não são bem vistas entre os outros funcionários do posto e esses funcionários não permanecem muito tempo na empresa. Aliás, a rotatividade dos funcionários é alta, em média eles permanecem 6 (seis) meses na empresa.

Entre os principais relatos que resumem a visão dos funcionários, destacam-se:

Ao chegar na cidade, muitos turistas se encontram desorientados ou sem informação alguma sobre o turismo na cidade, além do mais óbvio. Ao encontrarem um posto de informações, eles esperam que suas dúvidas sejam resolvidas da maneira mais simples e precisa possível, fazendo com que sua estadia na cidade seja a mais agradável que puder. (Funcionária atuante no posto de informação de Copacabana)

"Penso que deixar o turista confiante e receptivo é importante para que ele tenha boas recordações da viagem." (Funcionária atuante no posto de informação do Aeroporto Internacional do Galeão).

"Meu trabalho é muito importantepara o visitante. Explicar e ensinar sobre tudo o que ele pode fazer na nossa cidade é muito interessante. Graças a dicas que dou, o turista pode economizar nos city tours e mostro como éfácil viver na cidade." (Estagiária atuante no posto de informação do CIAT).

Por fim, uma funcionária resume a situação e sentimento de todos os funcionários com a seguinte frase:

"Acredito que meu atendimento seja favorável na noção de hospitalidade da cidade, agregando ao meu conbecimento e buscando prestar melhores informaçôes, apesar das dificuldades administrativas e estruturais da empresa." (Funcionária atuante no posto de informação do Aeroporto Santos Dumont).

A partir da análise da postura dos funcionários diante da função que desempenham, observa-se que, apesar da ausência de hospitalidade interna por parte da empresa, a boa vontade com que recepcionam o turista traz crescimento pessoal e profissional a eles. Os funcionários desejam que cada visitante tenha a melhor experiência dentro da cidade onde vivem e têm consciência de como esse bem receber é importante. Baseada nisso, cita-se Neves e Alexandre (2006, p. 1), "a interação entre culturas distintas por meio do serviço prestado ou pelo simples ato de acolher o outro simboliza e representa o caráter hospitaleiro em benefício mútuo aos envolvidos nas relações sociais proporcionadas pelo movimento turístico mundial no século XXI." (NEVES; ALEXANDRE, 2006, p. 1).

\subsection{E os turistas, como avaliam a hospitalidade recebida?}

Quanto aos turistas, foram entrevistados 35 visitantes (nacionais e internacionais) que passaram pelos postos de informação no período de 20 de maio a 13 de junho de 2015, nos postos da Urca, Aeroporto Santos Dumont, Candelária e Copacabana. Segue relatório com a análise dos dados: em relação à quantidade e localização de quiosques distribuídos pela cidade, $57,1 \%$ dos turistas relataram visitar poucos postos (em média dois ou três), entre os mais citados estão os da Urca, Copacabana, Rodoviária Novo Rio e Aeroportos, pois são situados em locais de maior movimentação. Citaram o quiosque da orla de Copacabana como um posto "curinga", pois se trata de um posto localizado próximo aos seus hotéis, o que permitia que tirassem diversas dúvidas durante seus passeios pela orla.

Assim, constata-se que o turista não é sensível à ausência de postos em determinada localidade, pois geralmente, onde encontram, tiram suas dúvidas gerais, pegam material informativo e não sentem necessidade de recorrer novamente ou localizar um quiosque em todo local que visitam. A parcela de turistas que fez algum tipo de crítica ou complemento citou a ausência de postos próximos à estação de embarque do Trem do Cristo Redentor; e recomendaram que todos os postos terceirizassem a venda de ingressos para atrativos turísticos, como Corcovado, Pão de Açúcar e para partidas de futebol no Maracanã, assim como os quiosques 
de Copacabana e Candelária realizam. Um casal de turistas de São Paulo visitou as cidades de Angra dos Reis e Paraty e, em relação à localização de postos, elogiou o Rio de Janeiro, pois os encontrara mais facilmente.

Questionados sobre as informações recebidas e preparo dos funcionários nos postos que visitaram, a maioria dos entrevistados (86\%) relatou que tiveram suas dúvidas sanadas e que sentiram segurança nas informações passadas, logo, observa-se opinião semelhante entre funcionários e visitantes no que se refere à eficiência da informação. Os poucos turistas (2\%) que apresentaram críticas citaram desconhecimento de alguns funcionários sobre ensaios de escolas de samba e visitação, atrativos turísticos e acesso ao Parque Nacional da Tijuca, além de um casal de Brasília que relatou ser atendido no quiosque de Copacabana por um funcionário grosseiro e pouco atencioso que informou errado a localização de um restaurante.

Por muitas vezes, o momento da aplicação do questionário era o primeiro contato do visitante com o material, assim, não era possível obter suas opiniões sobre este. Aqueles que já conheciam os materiais previamente (apenas 37,1\% dos entrevistados), por terem tido acesso a eles em hotéis ou outros postos, classificaram-nos como bons e completos.

Também foi de interesse da presente pesquisa obter informações sobre a opinião dos turistas referente à locomoção na cidade através da utilização de transporte público e auxílio das placas de trânsito. Entre os entrevistados, foram observados dois grupos: os que utilizaram transportes públicos e uma parcela maior que prefere a locomoção por táxi. Entre os que utilizaram transporte público, $60 \%$ classificaram como eficientes e práticos, relataram que as linhas de ônibus são suficientes, interligadas com outros meios de transporte e que não demoram muito.

Segundo relato positivo de um turista de São Paulo, o transporte do Rio de Janeiro está melhor que o de sua cidade. Por outro lado, um turista de Brasília disse que a sinalização de trânsito indicando pontos turísticos só começa a ser observada nas ruas já próximas ao ponto de interesse. As críticas que existiram foram relacionadas: ao intervalo do ônibus especial para o aeroporto internacional Antônio Carlos Jobim (em média 40 minutos), à falta de sinalização no centro da cidade (o que fez um casal de turistas de Brasília se perder), e ao fato de raríssimos funcionários dos serviços de transportes públicos falarem inglês, segundo turistas da Califórnia, o que os impossibilitavam de ter informações. Ainda, dos entrevistados, 28,5\% utilizaram o táxi como principal ou único meio de locomoção, entre os motivos citados estão o sentimento de segurança, a facilidade de não precisarem fazer baldeação entre transportes, e por considerarem a corrida mais barata do que em alguns estados brasileiros.

Por fim, questionaram-se os turistas sobre como sentiram a hospitalidade e receptividade da cidade. A maioria dos entrevistados $(85,7 \%)$ destacou o bom humor e alegria do carioca, além da constante referência à beleza da cidade como fator de influência no bem-estar e paixão do visitante. Segundo o relato de turistas: "Os cariocas são simpáticos e receptivos, parecem estar sempre de bom humor." (Turista de Minas Gerais).

Entre as críticas recebidas, destacam-se relatos de mau atendimento nos estabelecimentos de serviços pagos, como restaurantes, mercados e táxis, onde se observou constantemente maus tratos e rispidez com o turista. Porém, em geral, os relatos sobre hospitalidade na cidade se referem de forma positiva ao bem receber do carioca nas ruas e centros de convivência e no "astral" da cidade.

\section{CONSIDERAÇÕES FINAIS}

Apesar de a atividade turística ter modificado o caráter gratuito da hospitalidade, transformando-a em serviço recebido mediante pagamento direto ou indireto, a satisfação do turista ainda depende de atitudes desinteressadas e do sentimento de ser bem quisto na cidade destino, a fim de que se anulem as sensações de insegurança e estranhamento. Essa comercialização do turismo não aniquilou a dádiva do bem receber, herança da hospitalidade, apenas a incorporou nos equipamentos e serviços do turismo.

A ineficiência do domínio público quanto à organização de uma cidade reflete negativamente na relação de pertencimento e autoestima da população, resultando em um sentimento de não coletividade e identidade e, 
consequentemente, na inospitalidade ao visitante. Assim, defende-se neste trabalho, a ideia fundamental de ação conjunta entre o poder público e os órgãos de turismo no planejamento turístico e urbano hospitaleiro, a fim de alinhar a organização e estruturação dos recursos turísticos disponíveis, tendo como resultado a maior interação e bem-estar social. Acontece que os serviços turísticos de recepção enfrentam um paradoxo: a realidade de um funcionário que carrega a responsabilidade de ser a primeira impressão do turista, seja no aeroporto, no hotel ou no balcão de informações turísticas, versus sua formação ineficiente e baixa qualificação, o que compromete a confiança que o funcionário passa ao visitante e, consequentemente, a imagem da empresa e/ou cidade.

A empresa em questão, mesmo sendo renomada no meio turístico e bem-sucedida em ações de marketing da cidade do Rio de Janeiro, possui deficiências na gestão dos quiosques e no tratamento com seus funcionários. Não é novidade que um funcionário satisfeito com seus benefícios, remuneração, condições de trabalho e valorização profissional reflete isso na execução de seu trabalho e proporciona ao turista o tratamento e hospitalidade que merece como indivíduo e como cliente.

É de extrema importância a existência de um treinamento eficiente, que dê segurança ao funcionário que deseja exercer com plenitude sua missão de informar bem o turista que recebe, passando uma imagem confiável. Na realidade, devido à complexidade do Rio de Janeiro como cidade turística, além da exigência de uma formação técnica ou superior em turismo, o treinamento realizado com os funcionários deveria ter maior aprofundamento. Partindo desse pressuposto, o treinamento deveria embasá-los por meio de conhecimentos gerais acerca do fluxo de turismo na cidade, perfil e necessidades dos visitantes, palestras sobre serviços e equipamentos de turismo, conhecimentos geográficos e cartográficos, visitas periódicas aos pontos turísticos para fins de aprimoramento, entre outros conhecimentos técnicos e gerais que preparassem o funcionário para que dê informação do que viu e vivenciou e não que somente leu em um guia.

Diariamente, nos postos de informação, os funcionários se deparam com a dificuldade de explicar ao turista que em uma cidade que se vende como turística e preparada para receber não existe transporte turístico de integração entre os principais pontos de interesse; ou que não é aconselhável visitar o centro histórico da cidade aos finais de semana, devido à segurança e policiamento ineficientes; ou que é melhor pagar mais caro por um táxi do que esperar o ônibus especial para os aeroportos que, por vezes, passa em horários irregulares; ou ainda informar ao turista estrangeiro que não é possível comprar ingressos on-line antecipados, pois o site solicita número de CPF (Cadastro de Pessoa Física) e não passaporte, evidenciando, assim, o despreparo da cidade em relação aos seus serviços e facilidades turísticas e o constante malabarismo que os funcionários devem fazer para driblar as dificuldades impostas e tornar a cidade mais agradável e hospitaleira.

Hospitalidade se refere às relações humanas, e, no âmbito das empresas, deve se dar de forma ambivalente entre empresa e funcionário, pois todas as empresas deveriam ter como premissa básica a noção de hospitalidade interna com foco no seu funcionário, para que o dele seja o cliente. Como verificado nas entrevistas com os funcionários, eles têm plena consciência da importância de seu trabalho na hospitalidade carioca, mas dependem de um planejamento estratégico no âmbito da prestação de serviços que valorize o funcionário e, só assim, o turista, pois o funcionário representa a empresa e/ou a cidade de forma a fazer a primeira impressão ser satisfatória ao visitante, mesmo que sua formação e preparo não estejam à altura do esperado.

Por outro lado, por meio das entrevistas realizadas com os turistas, constatou-se que o serviço de informações turísticas prestado pela Riotur é satisfatório para a maioria deles, uma vez que consideraram os postos bem distribuídos e localizados, o material completo e eficiente e os atendentes receptivos e preparados. Assim, avalia-se que o objetivo do serviço é alcançado: receber bem o turista, informá-lo, entretê-lo e facilitar sua locomoção pela cidade, porém, a visão do turista é superficial, já que nem todos conseguem identificar as falhas de atendimento e serviço que estão por trás.

Assim, os funcionários, como agentes internos, possuem enorme conhecimento do que se passa por detrás do atendimento que dedica aos seus turistas. Eles detectam toda e qualquer deficiência de sua empresa, de seu 
local e material de trabalho, de seu atendimento e de sua função e ainda assim se esforçam para manter seu sentimento hospitaleiro e sua empatia com o visitante, aquele sem identidade reconhecida.

O turista, apesar de sua sensibilidade e exigências aguçadas, não é alcançado, em ampla escala, pelos problemas internos da empresa ou pelas falhas de serviço que venham a acontecer. Valendo frisar que grande parte do sucesso do serviço de informações turísticas prestado pela Riotur deve-se ao caráter hospitaleiro e da empatia do funcionário. Contudo, observou-se que a simpatia do carioca e as belezas da cidade ainda fascinam o turista, porém, o reparo de problemas estruturais e serviços deficitários precisam se tornar prioridade para órgãos públicos e privados do turismo.

\section{REFERÊNCIAS}

CAMARGO, L. O. L. Hospitalidade. Coleção ABC do Turismo, 2. ed. São Paulo: Editora Aleph, 2004.

GRINOVER, L. A hospitalidade, a cidade e o turismo. Série Turismo. São Paulo: Editora Aleph, 2007.

. A hospitalidade na perspectiva do espaço urbano. Revista Hospitalidade, São Paulo, ano VI, n. 1, p. 04-16, jan.-jun. 2009. Disponível em: https://revhosp.org/hospitalidade/article/viewFile/214/284. Acesso em: 23 out. 2016.

. A hospitalidade urbana: acessibilidade, legibilidade e identidade. Revista Hospitalidade, São Paulo, ano III, n. 2, p. 29-50, 2. sem. 2006. Disponível em: https://revhosp.org/hospitalidade/article/view/191. Acesso em: 23 out. 2016.

MAUSS, M. 1974 [1923-24]. Ensaio sobre a dádiva. Forma e razão da troca nas sociedades arcaicas. In: MAUSS, M. Sociologia e Antropologia. v. II. São Paulo: Edusp.

NEVES, R.; ALEXANDRE, M. Consumo da hospitalidade na realidade pós-moderna. In: Convibra - Congresso Virtual Brasileiro de Administração, 3, 24 a 26 de nov. de 2006. Disponível em: http://www.convibra.com.br/ artigo.asp?ev=25\&id=1939. Acesso em: 9 out. 2016.

ORLA RIO. Riotur - Informações turísticas - QC15. Disponível em: http://orlario.com.br/Site/rioturinformacoes-turisticas-qc15/. Acesso em: 23 out. 2016.

PREFEITURA DO RIO DE JANEIRO. Empresa de Turismo do Município do Rio de Janeiro - Riotur. Riotur Conheça a Secretaria. Disponível em: http://www.rio.rj.gov.br/web/riotur/exibeConteudo?article-id=92561. Acesso em: 19 abr. 2015.

PREFEITURA DO RIO DE JANEIRO. Riotur disponibilizará 17 postos de informação para turistas durante JMJ. Disponível em: http://www.rio.rj.gov.br/web/guest/exibeconteudo?id=4246072. Acesso em: 21 maio 2015.

RIOTUR. Empresa de Turismo do Município do Rio de Janeiro. Livro Guia do Rio. Rio de Janeiro, 2015.

SEVERINI, V. F. Hospitalidade Urbana: ampliando o conceito. Revista Iberoamericana de Turismo, Penedo, v. 3, n. 2, p. 84-99, 2013. Disponível em: http://www.seer.ufal.br/index.php/ritur/article/view/991. Acesso em: 23 out. 2016.

SILVA, E. L. da; MENEZES, E. M. Metodologia da pesquisa e elaboração de dissertação. 4. ed. rev. atual. Florianópolis: UFSC, 2005. 138 p.

VISIT RIO. Disponível em http://visit.rio/ . Acesso em: 23 out. 2016.

\section{Notas}

[1] Pesquisa realizada de março a julho de 2015.

\section{BY}

